\title{
Las formaciones yesíferas del Triásico Superior y Jurásico Inferior de Camarasa, en el frente Surpirenaico Catalán
}

\section{The gypsum formations of the Upper Triassic and Lower Jurassic of Camarasa, in the Catalan South Pyrenean front}

\author{
J.M. Salvany \\ Dept. Enginyeria Civil i Ambiental, Universitat Politècnica de Catalunya, c/ Jordi Girona 1-3, 08034 Barcelona. \\ Email: josepm.salvany@upc.edu; ORCID ID: http://orcid.org/0000-0003-1409-707X
}

\section{RESUMEN}

\begin{abstract}
En el presente estudio se describen las características litoestratigráficas de las formaciones yesíferas de Canelles (Keuper inferior) y de Lécera (Jurásico Inferior) aflorantes en la zona de Camarasa, en el frente Surpirenaico Catalán. La serie de la Fm. Lécera constituye una alternancia cíclica de capas de yesos y carbonatos de cerca de $300 \mathrm{~m}$ de espesor. El yeso es de litofacies laminada gris, laminada blanca y masiva blanca. Los carbonatos son brechas dolomíticas y dolomicritas finamente estratificadas. Por el contrario, la Fm. Canelles forma una serie yesífera masiva de $100 \mathrm{~m}$ de espesor, con capas menores de carbonato restringidas a la base de la formación y a su parte media. En la base el carbonato es de litofacies dolomicrita laminada, mientras que en la parte media es de litofacies margodolomía laminada, dolomicrita laminada y oolítica, formando cuatro ciclos de pocos metros de espesor. Ambas formaciones se originaron en sistemas evaporíticos de tipo lagoon sulfatado, muy estables, alimentados por aguas marinas y alejados de la influencia de aportes detríticos. En estos lagoons la sedimentación fue principalmente yesífera, en facies laminada, y con niveles subordinados de carbonatados, representando respectivamente estadios de mayor y menor concentración relativa del agua, y sin registro de sales más solubles (halita).
\end{abstract}

Palabras clave: Litoestratigrafía; Yeso; Keuper inferior; Jurásico Inferior; Camarasa.

\section{ABSTRACT}

The present study describes the lithostratigraphic characteristics of the Canelles Gypsum Formation (lower Keuper) and the Lécera Gypsum Formation (Lower Jurassic) in the area of Camarasa, in the Catalan South Pyrenean front. The Lécera Formation forms a cyclic alternation of gypsum and carbonate layers of about $300 \mathrm{~m}$ thick. Gypsum displays gray laminated, white laminated, and white massive lithofacies. Carbonate forms minor layers of dolobreccia and thin bedded dolomicrite lithofacies. On the contrary, the Canelles Formation forms a $100 \mathrm{~m}$ thick massive sequence mainly composed of white and brown laminated gypsum, with carbonate layers restricted to the base of the formation and to its middle part. On the base, the carbonate layers consist of laminated dolomicrite lithofacies, while in the middle part they display laminated dolomarl, thin bedded dolomicrite and oolitic lithofacies, which are arranged in four carbonatic cycles of few meters thick. Both formations originated in similar evaporitic environments of very stable sulfate lagoons fed by sea water and away from the influence of detrital inputs. In such lagoons sedimentation mainly consisted of laminated gypsum with minor carbonate beds, representing sediments of relatively high and low concentration of the lagoon water respectively, but without precipitation of more soluble salts (halite).

Keywords: Lithostratigraphy; Gypsum; Lower Keuper; Lower Jurassic; Camarasa.

Recibido el 28 de junio de 2017; Aceptado el 10 de agosto de 2017; Publicado online el 10 de noviembre de 2017

Citation / Cómo citar este artículo: Salvany, J.M. (2017). Las formaciones yesíferas del Triásico Superior y Jurásico Inferior de Camarasa, en el frente Surpirenaico Catalán. Estudios Geológicos 73(2): e070. http://doi.org/10.3989/egeol.42914.460.

Copyright: (c) 2017 CSIC. This is an open-access article distributed under the terms of the Creative Commons Attribution-Non Commercial (by-nc) Spain 3.0 License. 


\section{Introducción}

El pueblo de Camarasa se sitúa en el cruce del valle del río Segre con el frente del cabalgamiento surpirenaico, constituido por las sierras de Mont-roig y Carbonera, sobre la cuenca de antepaís del Ebro (Fig. 1). En esta zona afloran una amplia variedad de formaciones sedimentarias mesozoicas y paleógenas, deformadas en mayor o menor grado por la tectónica surpirenaica, que han sido descritas principalmente en los estudios estratigráficos y estructurales de Garrido \& Ríos (1972), Pocoví (1978a, 1978b), Martínez Peña \& Pocoví (1988), Sáez et al. (1991), Vergés (1993), Ullastre \& Masriera (1995, 1996), Saula \& Samsó (1996), Moragas et al. (2013), Soto et al. (2015), así como en la cartografía geológica 1:50.000 del Institut Geològic de Catalunya (IGC, 2006, 2010). Como un aspecto destacable, la zona incluye diversas formaciones yesíferas, de distintas edades y orígenes sedimentarios. Estas formaciones son, de Norte a Sur (Fig. 2): (1) los yesos del Jurásico Inferior, que se extienden al pie de las sierras de Mont-roig y Carbonera, formando un continuo afloramiento de hasta $8 \mathrm{~km}$ de longitud, que se reconoce bien en el paisaje por su característico color blanco debajo de las formaciones calizas grisáceas y rojizas de estas sierras; (2) los yesos del Triásico Superior (Keuper), que engloban barras carbonatadas del Muschelkalk y bloques de ofitas, formando en conjunto una franja discontinua de afloramientos de compleja estructura, cabalgada por los yesos jurásicos; y (3) los yesos del tránsito Eoceno-Oligoceno, que forman una estrecha franja en el antepaís plegado (anticlinal de Cubells) adosada al frente Surpirenaico. Las características de estas formaciones yesíferas son similares y han dado lugar a algunas confusiones en su atribución estratigráfica. Sin embargo, presentan claras diferencias en su composición y estructura sedimentaria, hasta ahora poco documentadas.

El presente estudio tiene por objetivo profundizar en las características litoestratigráficas de las unidades yesíferas del Keuper y del Jurásico de la zona de Camarasa (Figs. 1 y 2), y establecer criterios para una clara diferenciación entre ellas. Incluye: la cartografía geológica del área de estudio, las series estratigráficas levantadas en el campo, y el control mineralógico (difracción de rayos-X) y petrológico (lámina delgada) de sus diferentes litofacies. Para los yesos del Jurásico se presenta una serie prácticamente completa de esta unidad, en continuidad estratigráfica normal con las unidades carbonatadas suprayacentes y limitada inferiormente por falla. Para el Keuper el estudio se limita sólo a su parte inferior (Fm. Canelles, de Salvany \& Bastida, 2004), en continuidad estratigráfica normal sobre los depósitos carbonatados del Muschelkalk. La parte superior de la

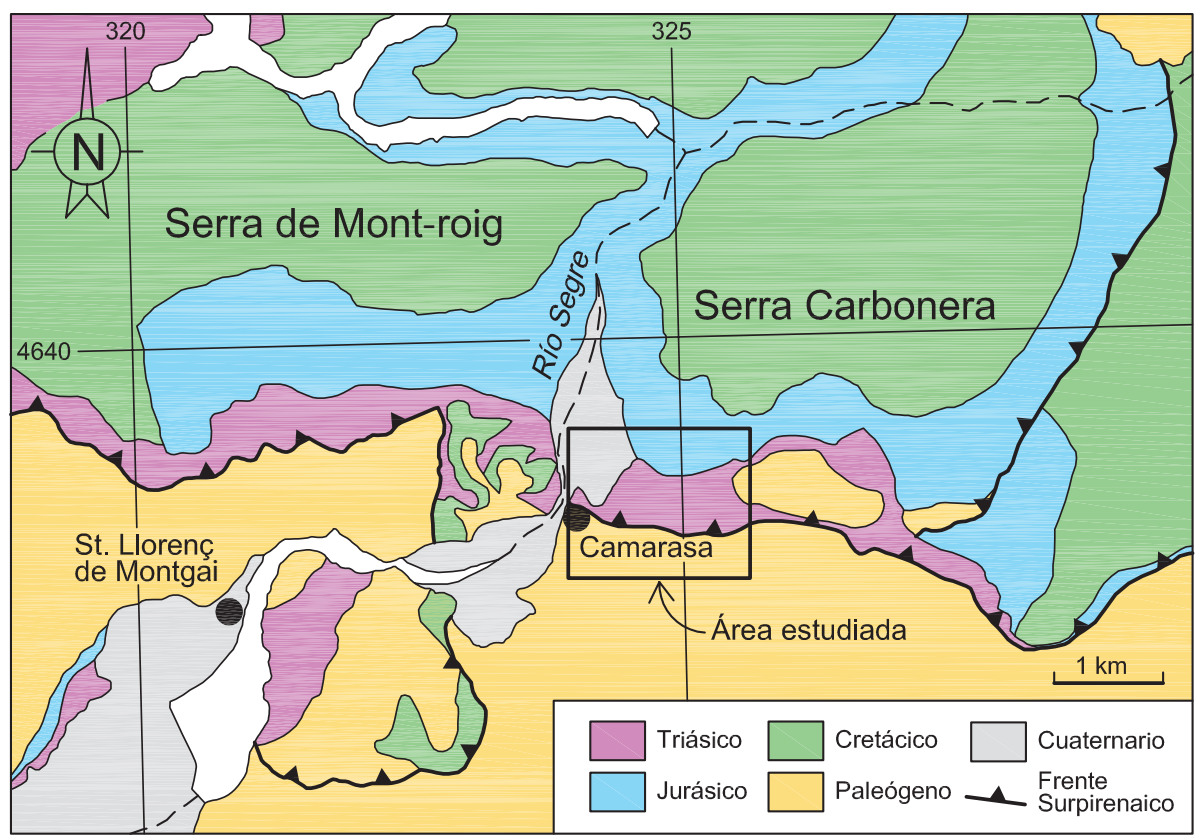

Fig. 1.-Mapa geológico de la zona de intersección del valle del río Segre con el frente surpirenaico, con situación del área de estudio (simplificado del IGC, 2006). Coordenadas UTM 31N. 


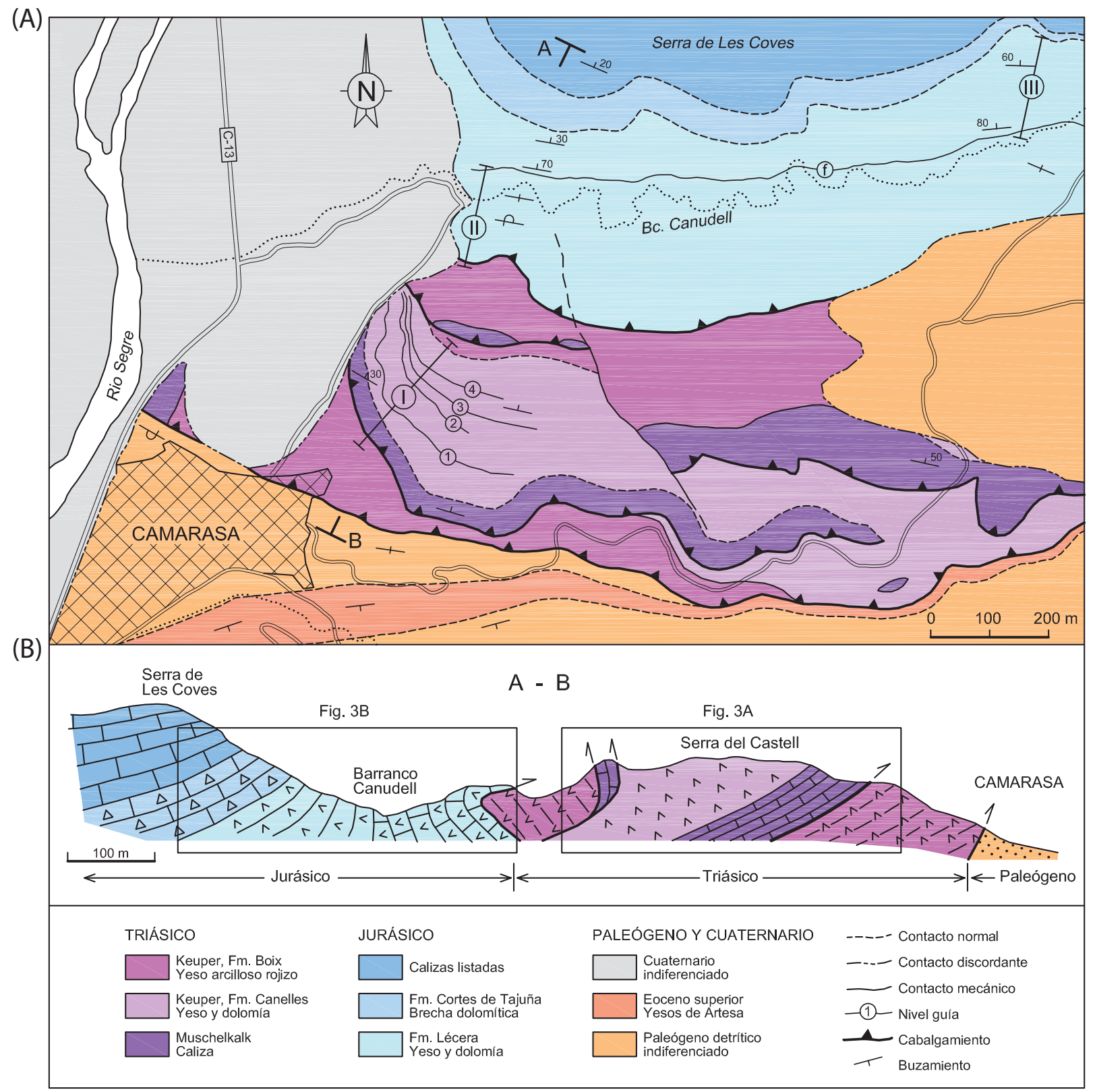

Fig. 2.-(A) Mapa geológico del área de estudio con situación de los cortes estudiados (I, II y III) del Keuper y Jurásico Inferior. (B) Corte geológico del escarpe oriental del valle del río Segre.

serie está incompleta y muy alterada por la tectónica y la meteorización, y no permite ser estudiada en detalle. Se discute también las similitudes y diferencias sedimentológicas entre ambas formaciones.

\section{Marco estratigráfico}

En el área estudiada, los materiales más antiguos aflorantes son los del Muschelkalk. Forman una serie carbonatada en la que se pueden distinguir dos unidades principales (Fig. 3A): una unidad inferior masiva, de $12 \mathrm{~m}$ de espesor, compuesta por capas de caliza micrítica de espesor métrico; y una unidad superior de calizas tableadas de $24 \mathrm{~m}$ de espesor. Esta segunda unidad culmina con un característico nivel bioclástico (grainstone de equinodermos y gasterópodos) que marca el techo de la serie (nivel guía). Estas unidades son equivalentes, respectivamente, 


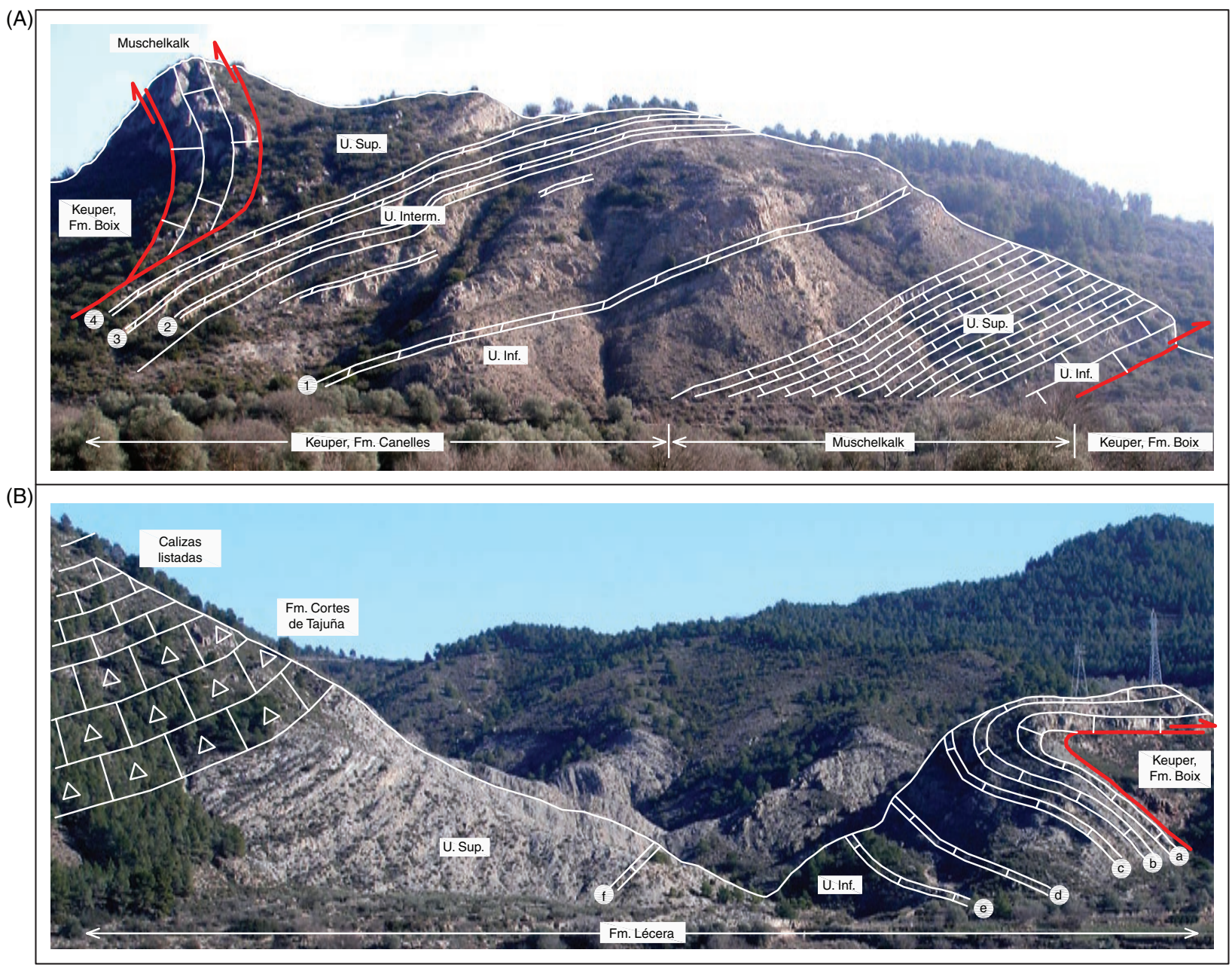

Fig. 3.-Detalles del corte de la figura 2B. (A) Muschelkalk y Keuper; (B) formaciones Lécera y Cortes de Tajuña.

a la "Unidad de Calizas grises" y a la "Unidad de Calizas y/o dolomías tableadas" de Calvet et al. (1994), atribuidas al Ladiniense-Carniense basal.

El Keuper está representado por dos unidades claramente diferenciables por el color de sus materiales: una unidad inferior bien estratificada, de yeso blanco con capas subordinadas de carbonato; y una unidad superior de yeso arcilloso rojizo. Corresponden, respectivamente, a las formaciones Canelles y Boix, de Salvany \& Bastida (2004), de edad Carniense. La Fm. Canelles aflora escasamente deformada $\mathrm{y}$ en continuidad estratigráfica normal sobre el Muschelkalk, con un espesor próximo a los $100 \mathrm{~m}$. La Fm. Boix aflora siempre muy alterada por la tectónica y la meteorización. No se reconoce la Fm. de Les Avellanes (Salvany \& Bastida, 2004), que representa la parte superior de la serie del Keuper en todo el dominio surpirenaico, y que alcanza hasta $100 \mathrm{~m}$ de espesor en zonas próximas a Camarasa. Tampoco se reconocen las "Calizas Inferiores" de Garrido \& Ríos (1972) o Fm. Isàbena de Arnal et al. (2002), que caracterizan el techo de la serie triásica surpirenaica, ni las unidades basales del Jurásico Inferior ("Brecha ferruginosa" y "Caliza de ostrácodos" de Garrido y Ríos, 1972). Se entiende que estas unidades en la zona de estudio han estado laminadas por la tectónica y no llegan a aflorar.

Los yesos del Jurásico Inferior tienen un espesor del orden de $300 \mathrm{~m}$. Constituyen una monótona sucesión de yesos grises y blancos que incluyen frecuentes capas de carbonato de hasta varios metros de espesor en la parte inferior de la serie, y gradualmente de menor espesor hacia el techo de la misma (Fig. 3B). Esta unidad yesífera ha sido descrita en el 
área surpirenaica por Garrido y Ríos (1972) y Fauré (1984) como parte de una unidad más amplia a la que denominan, respectivamente, "Brecha dolomítica" y "Complejo evaporítico basal". A escala peninsular, estos yesos han sido denominados Fm. Lécera en la Cordillera Ibérica por Gómez \& Goy (1998). En los trabajos posteriores de Gómez et al. (2007) y Ortí et al. (2017) esta denominación se ha utilizado en otras regiones peninsulares donde esta unidad yesífera está también desarrollada. En el presente estudio se ha optado por seguir con esta misma denominación.

Por encima de los yesos jurásicos de Camarasa se identifica una unidad masiva de brecha dolomítica, de hasta $40 \mathrm{~m}$ de espesor en el extremo occidental del área de estudio, que se acuña gradualmente hacia el Este hasta tener sólo unos pocos metros (Fig. 2A). El contacto con los yesos subyacentes es neto, probablemente erosivo. Para esta unidad se ha optado por la denominación Fm. Cortes de Tajuña, que es el nombre que reciben estas brechas situadas por encima o lateralmente equivalentes a los yesos jurásicos en la Cordillera Ibérica (Cadillac et al., 1981; Gómez \& Goy, 1998), así como en otras regiones peninsulares (Ortí, 1987; Ortí et al., 2017).

Por encima de la brecha dolomítica, se presenta una unidad de calizas y dolomías bien estratificadas, de hasta $30 \mathrm{~m}$ de espesor, denominada "calizas listadas y dolomías" por Garrido y Ríos (1972), que podría ser equivalente a la Fm. Cuevas Labradas de Gómez \& Goy (1998).

Todas estas formaciones jurásicas son azoicas pero han sido atribuidas al Hettangiense superiorSinemuriense al situarse por debajo de una unidad de margas fosilíferas que marca la base del Jurásico Medio (Delmás et al., 1971).

El Paleógeno de Camarasa (tránsito EocenoOligoceno) ha sido descrito por Sáez et al. (1991, figura 19). Incluye: una unidad inferior limosa, con niveles de arenisca y yeso, y con un nivel basal de brechas, con un espesor total del orden de $100 \mathrm{~m}$; una unidad intermedia de yesos y lutitas grises, de $83 \mathrm{~m}$; y una unidad superior de lutitas con capas de arenisca y conglomerados a techo, del orden de 500 m. La unidad intermedia se conoce como "Yesos de Artesa" y ha sido descrita con cierto detalle en los estudios de Sáez (1987), Sáez et al. (1991) y Serra et al. (1992). Constituye un miembro de la Fm.
Barbastro, desarrollado entre los depósitos detríticos de la Fm. Solsona (Sáez, 1987). Equivale también a la unidad Y2 de Ullastre \& Masriera (1995).

\section{La Fm. Canelles (Keuper)}

El mejor lugar para el reconocimiento de la Fm. Canelles es el corte que forma el escarpe del margen oriental del valle del río Segre, al Norte del pueblo de Camarasa (Fig. 2, corte I, y Fig. 3A). Tiene fácil acceso tanto por la pista que bordea la base del escarpe, como por el camino que discurre por la parte alta del escarpe y que sale desde el final de una de las calles de la parte alta del pueblo. En este corte el Triásico forma tres láminas cabalgantes superpuestas (Fig. 2). La lámina inferior está compuesta por el yeso arcilloso rojizo de la Fm. Boix, que cabalga sobre el Paleógeno. La lámina intermedia está compuesta por el Muschelkalk y los yesos de la Fm. Canelles, que en conjunto forman una estructura monoclinal, inclinada hacia el norte, que cabalga sobre la lámina inferior. La lámina superior está compuesta por bloques despegados de la unidad masiva inferior del Muschelkalk y por los yesos de la Fm. Boix, que cabalgan sobre el techo de la Fm. Canelles de la lámina intermedia. A su vez, esta lámina superior es cabalgada por los yesos de la Fm. Lécera.

En la lámina intermedia, la serie de la Fm. Canelles aflora completa. En ella se pueden distinguir tres diferentes unidades (Fig. 4): unidad inferior yesífera con capas de carbonato, de $62 \mathrm{~m}$ de espesor; unidad intermedia carbonatada, de $18 \mathrm{~m}$ de espesor; y unidad superior yesífera de $16 \mathrm{~m}$ de espesor. Por encima de esta última unidad afloran puntualmente los yesos rojos de la Fm. Boix que, en esta lámina intermedia, están en contacto normal a techo de la Fm. Canelles.

\section{Unidad inferior}

La unidad inferior constituye una secuencia que desde su base hacia el techo pasa gradualmente de ser dominantemente carbonatada a ser dominantemente yesífera. Los primeros $15 \mathrm{~m}$ constituyen un tramo dolomicrítico laminado (Fig. 5A) que engloba también láminas de yeso. Por encima, se imponen los niveles de yeso sobre el carbonato, llegando a constituir el material dominante en la mitad superior de la unidad. En esta parte superior yesífera se identifican 


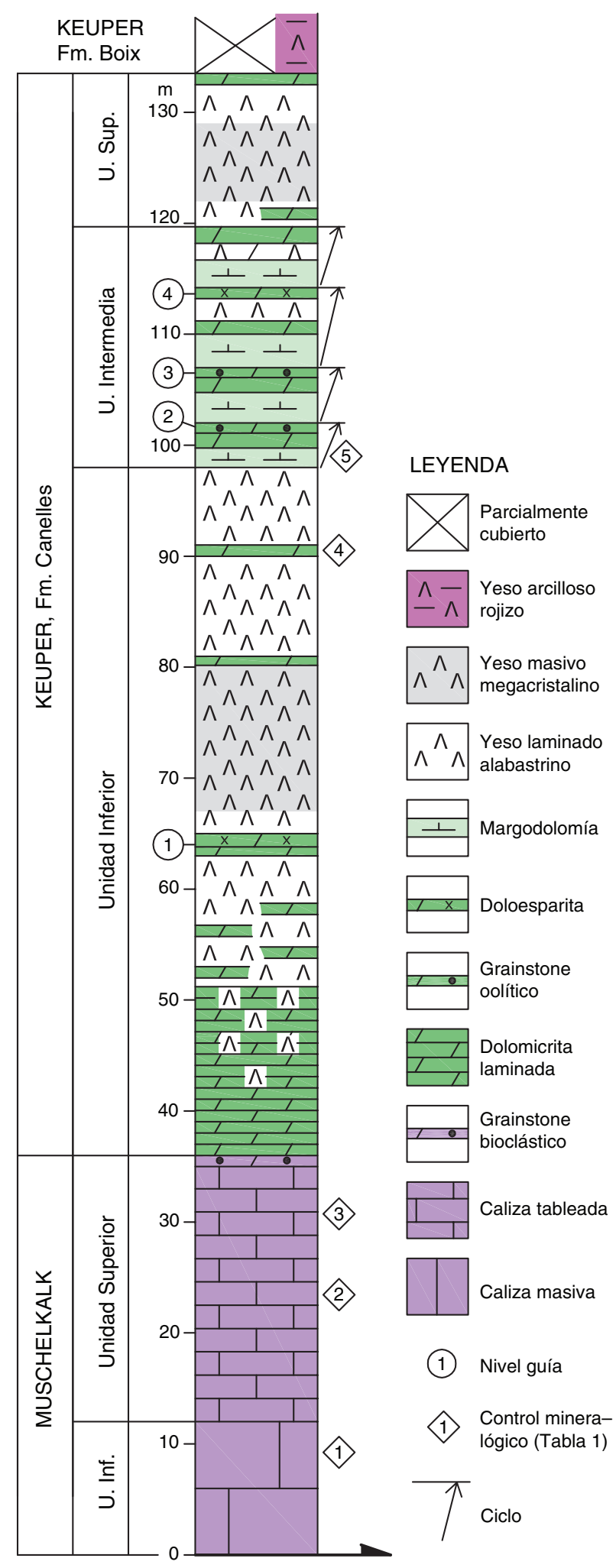

Fig. 4.-Columna litológica del Muschelkalk y Keuper (Fm. Canelles) correspondiente al corte I de la Fig. 2A. hasta tres capas dolomicríticas de espesor métrico. La inferior constituye un nivel guía de gran continuidad lateral (nivel guía 1 de las Figs. 2A y 3A).

El yeso es de litofacies laminada, blanco, gris o con tonos marrones (Fig. 5B), con mayor o menor desarrollo de láminas de carbonato dolomicrítico (Fig. 5C), y con textura secundaria alabastrina o megacristalina. En este segundo caso la textura enmascara la estructura laminada original y el yeso se muestra aparentemente en forma de capas masivas. Al microscopio, el yeso laminado muestra siempre cantidades apreciables de carbonato micrítico disperso o formando láminas compactas. Este yeso presenta abundantes pseudomorfos de cristales prismáticos (laths) de anhidrita (Fig. 6A) y lenticulares de yeso, más o menos orientados según la laminación. Las capas de carbonato son dolomicríticas, a veces también con pseudomorfos de anhidrita (Fig. 6B).

\section{Unidad intermedia}

La unidad intermedia presenta cuatro ciclos carbonatados (Fig. 4), que están compuestos por un nivel margodolomítico laminado inferior, un nivel dolomicrítico intermedio, y un nivel masivo oolítico superior (Fig. 5D). Los dos ciclos superiores intercalan también niveles de yeso laminado en su parte superior. En el nivel margodolomítico se han identificado estructuras de bioturbación (burrows). El nivel superior oolítico es el menos desarrollado, no superando los $40 \mathrm{~cm}$ de espesor, y se dispone en contacto neto (erosivo) sobre la dolomicrita intermedia. Los oolitos están en mayor o menor grado micritizados, y también en parte disueltos (Figs. 6C y D).

\section{Unidad superior}

La unidad superior constituye un tramo yesífero similar al de la parte superior de la unidad inferior, aunque de menor desarrollo (Fig. 4). Culmina con un nivel dolomicrítico sobre el que se disponen en contacto neto los yesos rojizos de la Fm. Boix.

\section{La Fm. Lécera}

En la formación Lécera pueden diferenciarse dos unidades litológicas (Fig. 7): una unidad inferior con importante desarrollo de capas de carbonato y uniformidad de yesos con litofacies laminadas; y 

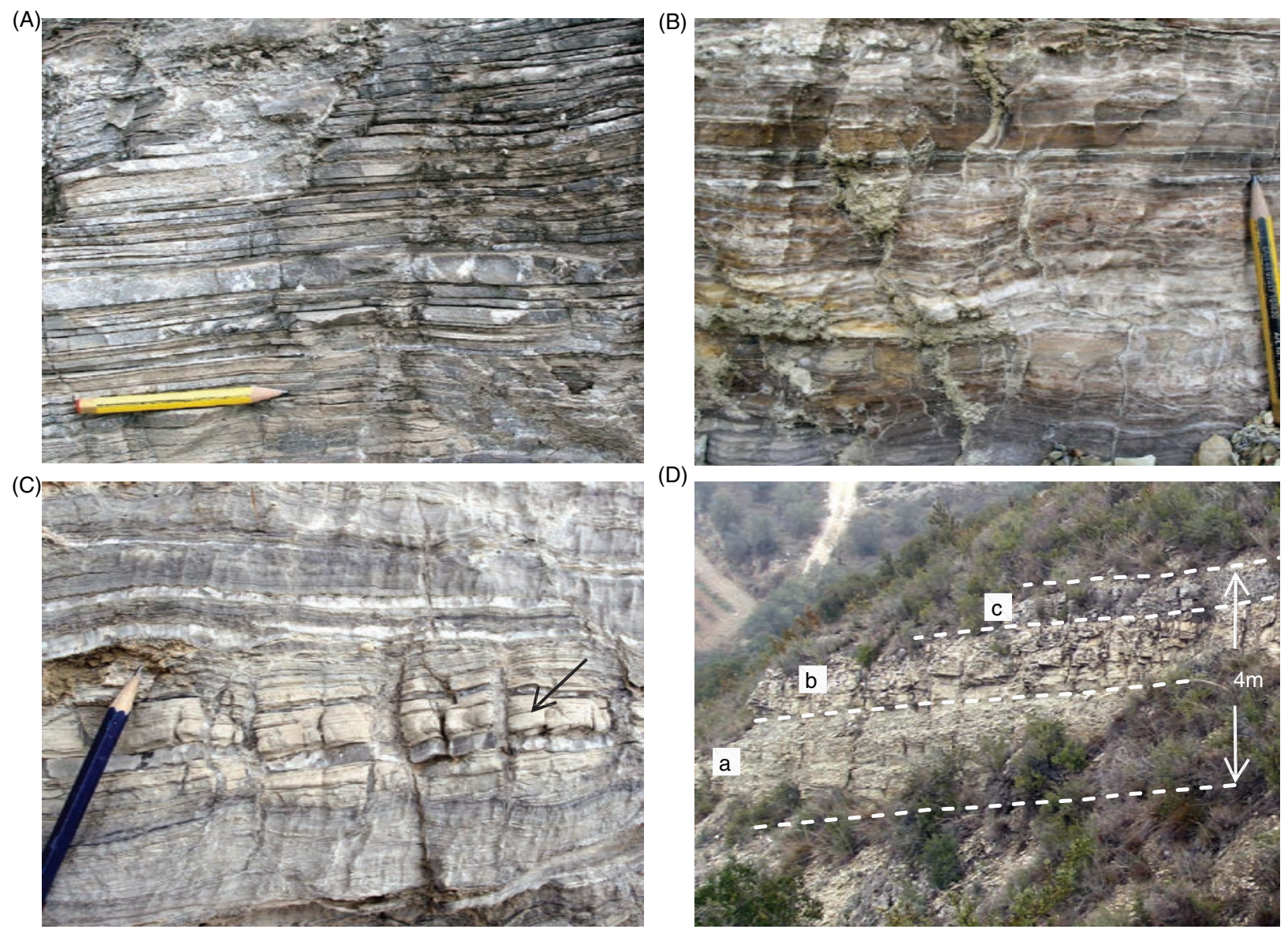

(D)

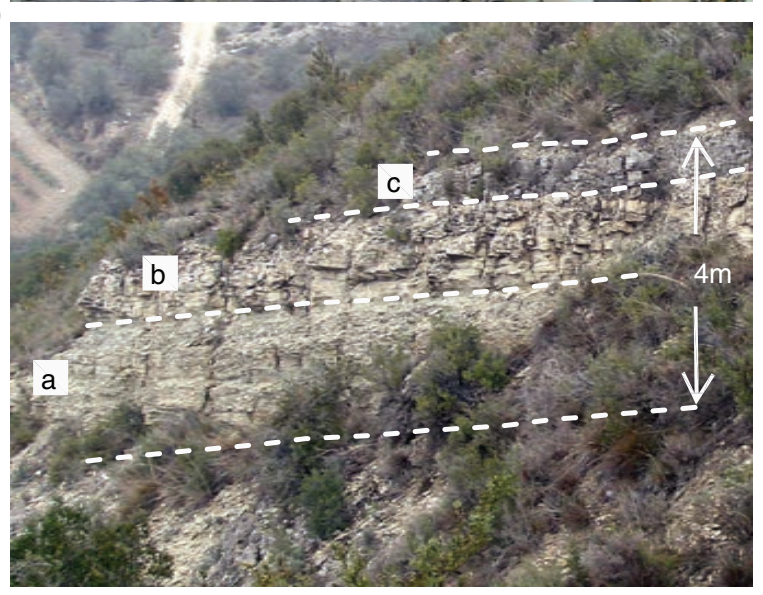

Fig. 5.-Litofacies de la Fm. Canelles: (A) dolomías laminadas de la base de la unidad inferior; (B) yeso con litofacies laminada en tonos marrones; (C) yeso blanco laminado con intercalación de láminas dolomicríticas (flecha); (D) Ciclo carbonatado inferior de la unidad intermedia en el corte I (Fig. 2A): (a) nivel margodolomítico laminado inferior, (b) nivel intermedio de dolomicrita tableada, (c) nivel oolítico superior.

una unidad superior con menor desarrollo de carbonatos y mayor variedad de litofacies yesíferas. El mejor corte para estudiar la unidad inferior es el que forma el escarpe del margen oriental de valle del río Segre, al que se accede fácilmente desde la carretera C-13 hacia Tremp, poco después de pasar el pueblo de Camarasa (Fig. 2A, corte II). En la zona de contacto con el Keuper, esta unidad está muy deformada y no queda claro si sus niveles inferiores son la base de la formación o bien ésta ha quedado en parte laminada por la tectónica (Fig. 3B). La unidad superior de la formación aflora mejor para su estudio en la parte alta del barranco del Canudell (Fig. 2A, corte III), que tiene también fácil acceso desde la pista que desde Camarasa sube hacia la ermita de Sant Jordi situada en la cumbre de la Sierra Carbonera. La correlación entre los dos cortes es fácil gracias a la existencia de un continuo nivel guía carbonatado (nivel guía "f") que se sigue bien a lo largo de todo el barranco del Canudell y que en el presente estudio se ha considerado como el límite entre ambas unidades. En este corte III, la serie es continua hasta la base de la brecha dolomítica, que en esta parte del área de estudio tiene unos pocos metros de espesor. En el corte de la pista, las capas de yeso del techo de la Fm. Lécera pasan directamente a la base de las "calizas listadas", sin ningún nivel de brecha entre ambas. En afloramientos más al Este del barranco del Canudell, la brecha aparece de nuevo. No queda claro si en el corte de la pista la brecha está ausente debido a algún accidente tectónico o por la estructura original de esta unidad que, como ya se ha dicho, es de desarrollo lateral muy variable. 

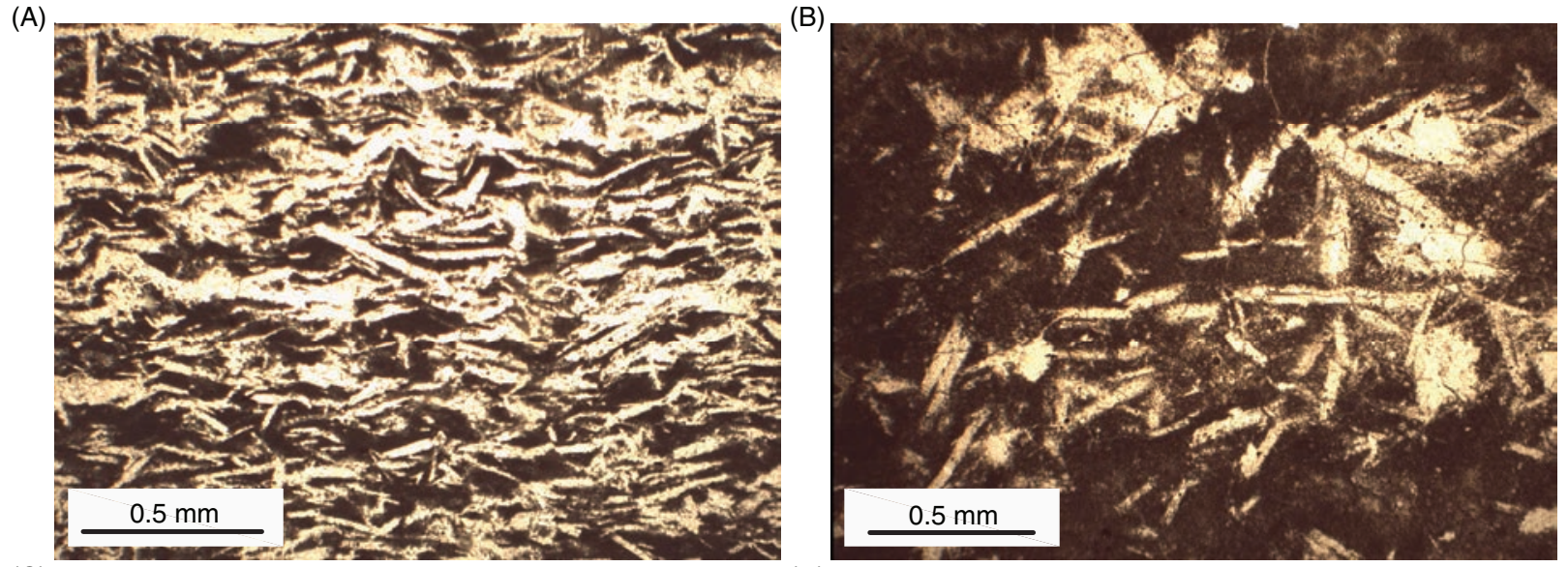

(C)

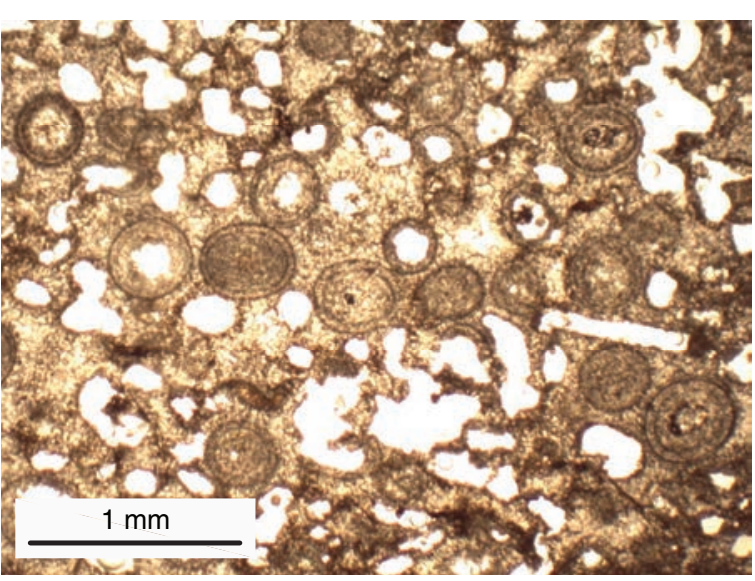

(D)

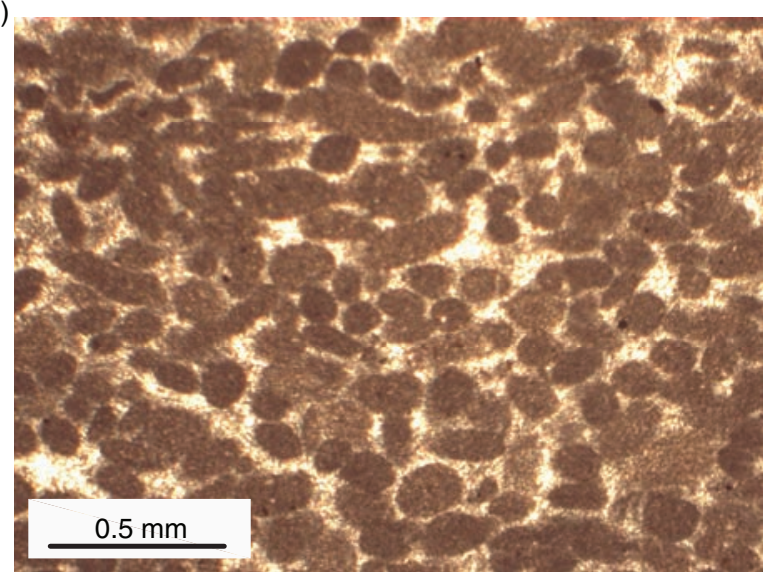

Fig. 6.-Microfacies de la Fm. Canelles: (A) yeso laminado con abundantes pseudomorfos de cristales prismáticos (lath) de anhidrita, correspondiente a la parte superior de la unidad inferior (Fig. 4); (B) dolomicrita con pseudomorfos en calcita de antiguos cristales prismáticos de anhidrita, correspondientes al nivel 1 de la unidad inferior; (C) grainstone de oolitos del techo del primer ciclo de la unidad intermedia. Algunos de los oolitos están parcial o totalmente disueltos; (D) grainstone de peloides interpretados como oolitos totalmente micritizados, del mismo nivel que $\mathrm{C}$. Todas las fotomicrografías están hechas en luz paralela.

\section{Unidad inferior}

En el corte II, la unidad inferior constituye una alternancia de capas de yeso y carbonato con un espesor total de $154 \mathrm{~m}$. El yeso es la litología dominante, formando tramos continuos de hasta $30 \mathrm{~m}$ de espesor, de litofacies laminada gris muy uniforme (Fig. 8C). Las capas de carbonato tienen hasta $5 \mathrm{~m}$ de espesor. Son dominantemente brechas dolomíticas, oquerosas, heterométricas, con clastos de hasta $20 \mathrm{~cm}$ de diámetro, de colores ocres (Fig. 8A). También forman niveles dolomicríticos finamente estratificados, de color gris claro (Fig. 8B). Ambas litofacies pueden estar presentes en una misma capa, formando niveles superpuestos o bien en tránsito lateral. En los 90 m inferiores, las capas de carbonato tienen varios metros de espesor y resaltan sobre los materiales yesíferos más blandos que las engloban. En la parte superior del corte, las capas de carbonato no superan $1 \mathrm{~m}$ de espesor y están muy descompuestas por la meteorización.

\section{Unidad superior}

En el corte III, la unidad superior tiene un espesor de $158 \mathrm{~m}$. Es esencialmente yesífera, con escaso desarrollo de niveles carbonatados, formando capas generalmente de menos de $50 \mathrm{~cm}$ de espesor. El yeso es dominantemente laminado gris, igual que en la unidad inferior, pero en esta unidad destacan también capas de yeso blanco, de litofacies laminada y masiva (Fig. 8D y E). Estas capas blancas presentan unos pocos metros de espesor. 


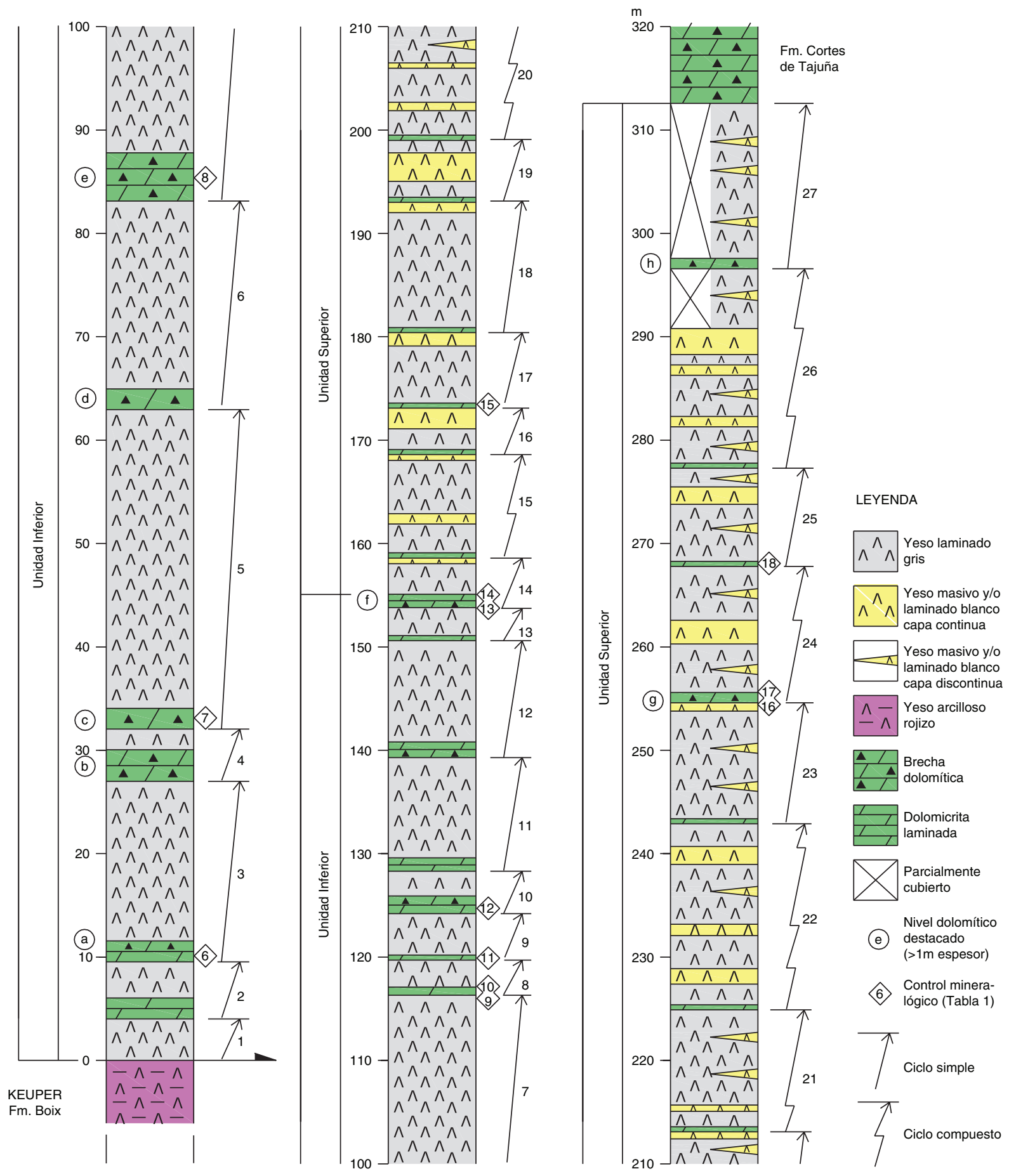

Fig. 7.—Columna litológica de la Fm. Lécera construida a partir de los cortes II y III de la figura 2A.

Pueden ser relativamente continuas lateralmente, hasta algunos centenares de metros, o bien formar niveles discontinuos englobados en el yeso gris, de unos pocos metros o decenas de metros. En general constituyen niveles que resaltan en la superficie del terreno al ser relativamente más resistentes a la erosión que el yeso gris que los engloba (Fig. 9). El yeso laminado blanco generalmente es puro 

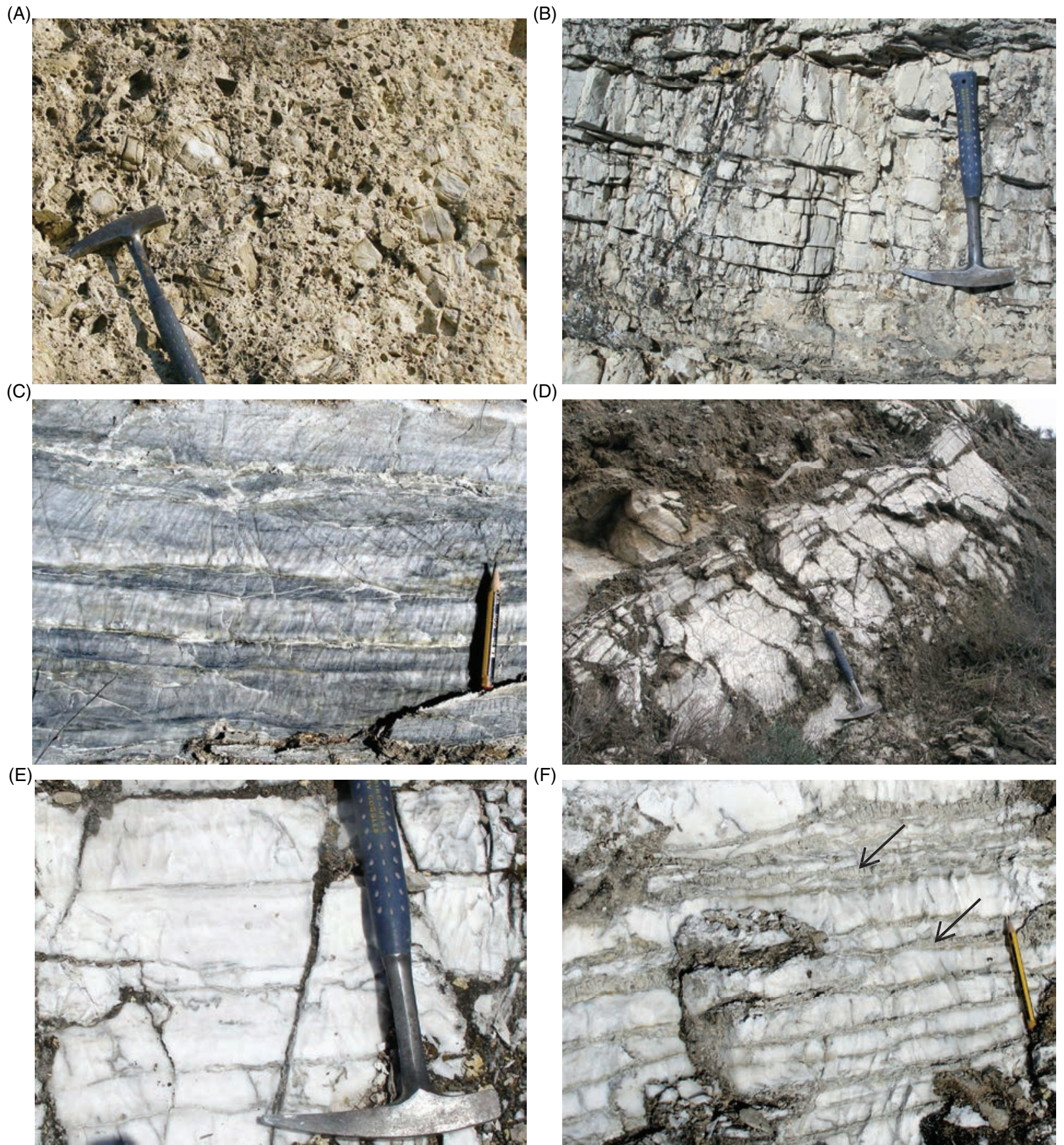

Fig. 8. - Litofacies de la Fm. Lécera: (A) brecha dolomítica del nivel b de la unidad inferior (Fig. 7); (B) dolomicrita tableada del nivel $\mathrm{C}$ de la unidad inferior; (C) yeso laminado gris; (D) capa de yeso blanco masivo que destaca entre capas de yeso gris alterado por encima y debajo; (E) yeso masivo blanco; $(F)$ yeso masivo blanco con intercalación de láminas de carbonato (flechas).

pero también puede contener láminas menores de carbonato (Fig. 8F). Las capas de yeso masivo suelen mostrar laminación difusa y alcanzan como máximo $30 \mathrm{~cm}$ de espesor. Al microscopio, el yeso gris y el yeso blanco son de aspecto alabastrino muy parecido, y muestran niveles de carbonato micrítico dispersos o formando finos niveles más compactos. A diferencia de los yesos del Keuper, raramente se observan pseudomorfos de cristales prismáticos de anhidrita. 


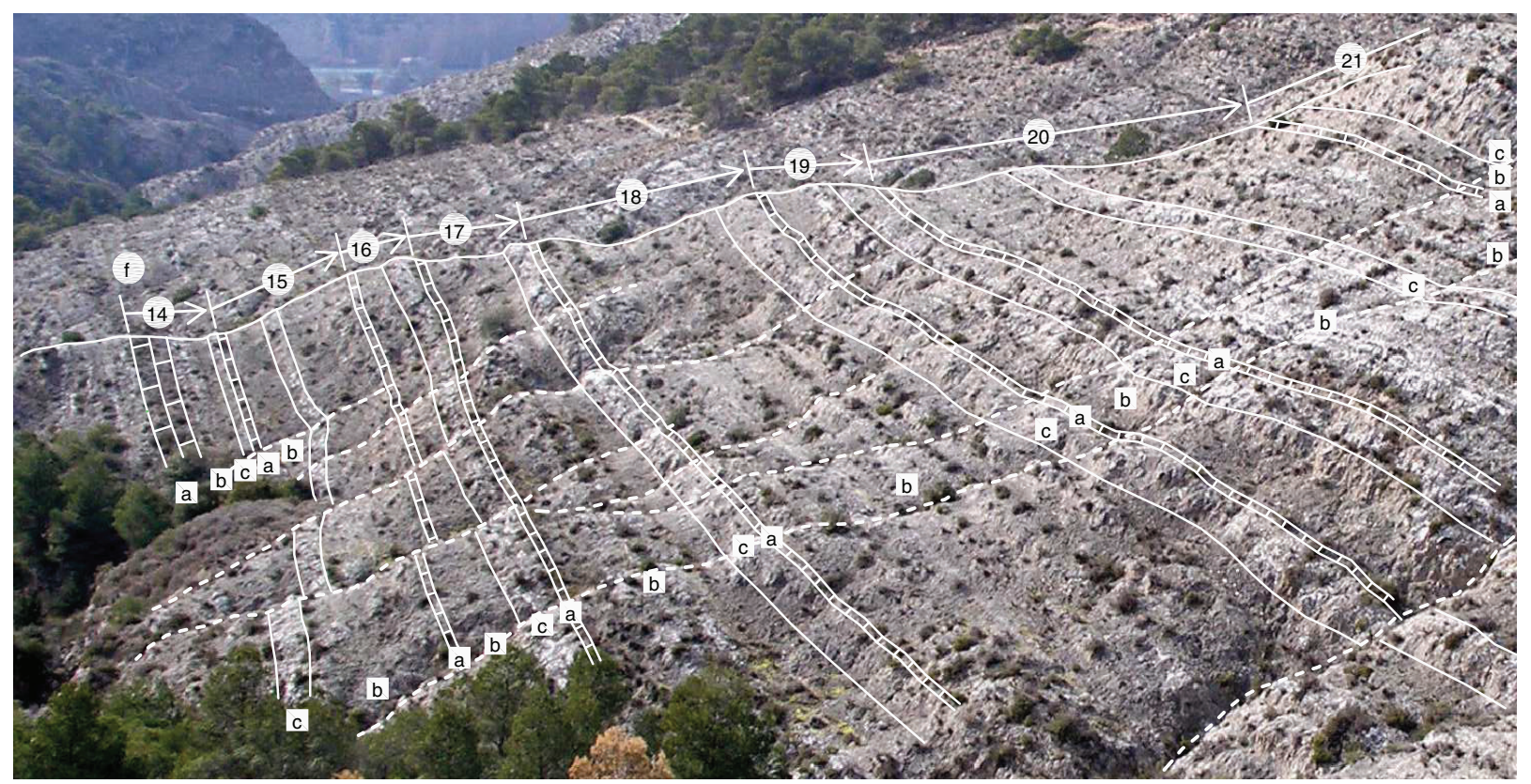

Fig. 9.-Ciclos evaporíticos 14 al 21 de la unidad superior de la Fm. Lécera en el corte III (Fig. 2A): (a) nivel carbonatado basal; (b) nivel intermedio de yeso laminado gris, con niveles discontinuos de yeso laminado blanco; (c) nivel superior de yeso blanco laminado o masivo en capas continuas.

Las capas de carbonato son de litofacies brecha dolomítica o dolomicrita laminada, similares a las de la unidad inferior. En algunos casos forman finas costras ocres de menos de $10 \mathrm{~cm}$. Excepcionalmente, pueden tener hasta $1 \mathrm{~m}$ de espesor (niveles g y h, Fig. 7). A pesar de su delgadez son capas relativamente continuas lateralmente.

\section{Ciclicidad}

En el conjunto de la serie, las capas de yeso y carbonato alternan en la vertical formando ciclos de espesor muy variable (Figs. 7 y 9). En la unidad inferior, se identifican 13 ciclos de entre 3 y $33 \mathrm{~m}$ de espesor. Están compuestos por una capa basal carbonatada de hasta varios metros de espesor, y una capa superior de yeso laminado gris también de gran espesor.

En la unidad superior, los ciclos (14 al 27) incluyen una mayor diversidad de litofacies de yeso. Son ciclos de entre 4,5 y $19 \mathrm{~m}$ de espesor y, en general, tanto el espesor de los ciclos como su complejidad aumentan hacia el techo de la serie. Pueden ser ciclos simples o compuestos. Un ciclo simple se compone de una capa basal carbonatada (a), una capa intermedia de yeso laminado gris que puede englobar niveles discontinuos de yeso blanco laminado (b), y una capa continua superior de yeso blanco laminado y/o masivo (c). Los ciclos compuestos son similares a los simples pero con desarrollo de niveles continuos de yeso blanco intercalados en el tramo yesífero gris intermedio.

En total, se han identificado 27 ciclos, con tendencia primero estrato-decreciente hasta el techo de la unidad inferior, y después estrato-creciente hasta el techo de la superior.

\section{Mineralogía de yesos y carbonatos}

Se ha estudiado la mineralogía de las diferentes litofacies de yeso y carbonato identificadas en el Muschelkalk, Fm. Canelles y Fm. Lécera, mediante lámina delgada (24 muestras) y difracción de rayos- $\mathrm{X}$ (18 muestras, Tabla 1).

Todos los yesos son de carácter secundario, procedentes del reemplazamiento de anhidrita. Son yesos principalmente de textura alabastrina, con niveles porfiroblásticos ocasionales, pero también de textura megacristalina en algunos tramos de la Fm. Canelles (Fig. 4). El yeso alabastrino reproduce bien la estructura laminada original del sedimento evaporítico. Por el contrario, el yeso megacristalino enmascara la 
Tabla 1.-Valores semi-cuantitativos en \% de minerales identificados mediante difracción de rayos-X, en muestras de carbonatos del Muschelkalk y de las formaciones Canelles y Lécera. Ver figuras 4 y 7 para su localización.

\begin{tabular}{|c|c|c|c|c|c|c|c|c|c|c|}
\hline Ref. & Litofacies & Unidad & Cal & Dol & $Q$ & Feld & Mic & $\mathrm{Y}$ & Cel & Mag \\
\hline 1 & Caliza masiva & Muschelkalk, U. Inferior & 96,00 & --- & 2,00 & $?$ & --- & $\begin{array}{c}-- \\
--\end{array}$ & 2,00 & --- \\
\hline 2 & Caliza tableada & Muschelkalk, U. Superior & 93,00 & --- & 4,00 & --- & --- & 3,00 & --- & --- \\
\hline 3 & Caliza tableada & Muschelkalk, U. Superior & 87,00 & --- & 6,00 & 7,00 & $?$ & --- & --- & --- \\
\hline 4 & Dolomicrita masiva & Keuper, Fm. Canelles, U. Inf. & -- & 87,90 & 2,00 & --- & --- & 9,10 & 1,00 & --- \\
\hline 5 & Margodolomía laminada & Keuper, Fm. Canelles, U. Interm. & 49,00 & 42,00 & 9,00 & $?$ & --- & --- & --- & --- \\
\hline 6 & Dolomicrita laminada & Fm. Lécera, U. Inferior & 1,00 & 99,00 & $?$ & --- & --- & --- & -- & --- \\
\hline 7 & Brecha dolomítica & Fm. Lécera, U. Inferior & 23,00 & 75,00 & 1,00 & --- & --- & --- & 1,00 & --- \\
\hline 8 & Brecha dolomítica & Fm. Lécera, U. Inferior & 9,00 & 91,00 & $?$ & $?$ & --- & --- & --- & --- \\
\hline 9 & Dolomicrita laminada & Fm. Lécera, U. Inferior & --- & 99,00 & 1,00 & --- & --- & --- & --- & --- \\
\hline 10 & Brecha dolomítica & Fm. Lécera, U. Inferior & 67,00 & 21,00 & 3,00 & --- & 7,00 & 2,00 & -- & --- \\
\hline 11 & Dolomicrita laminada & Fm. Lécera, U. Inferior & --- & 95,00 & $?$ & --- & --- & 5,00 & -- & --- \\
\hline 12 & Brecha dolomítica & Fm. Lécera, U. Inferior & 41,60 & 57,40 & 1,00 & --- & -- & -- & --- & --- \\
\hline 13 & Brecha dolomítica & Fm. Lécera, U. Inferior & 79,00 & 15,00 & 6,00 & --- & --- & --- & --- & --- \\
\hline 14 & Dolomicrita laminada & Fm. Lécera, U. Inferior & 2,00 & 97,00 & 1,00 & --- & --- & --- & --- & --- \\
\hline 15 & Brecha dolomítica & Fm. Lécera, U. Superior & 82,80 & 14,10 & 1,00 & --- & --- & 2,00 & --- & --- \\
\hline 16 & Brecha dolomítica & Fm. Lécera, U. Superior & 12,90 & 86,10 & 1,00 & --- & --- & --- & --- & --- \\
\hline 17 & Dolomicrita laminada & Fm. Lécera, U. Superior & 23,80 & 75,20 & 1,00 & --- & --- & --- & --- & --- \\
\hline 18 & Brecha dolomítica & Fm. Lécera, U. Superior & 84,00 & --- & 5,00 & --- & --- & 3,00 & 2,00 & 6,00 \\
\hline
\end{tabular}

Cal = calcita; Dol = dolomita; $\mathrm{Q}=$ cuarzo; Fel = feldespatos; Mic = micas; $\mathrm{Y}=$ yeso; Cel = celestina; Mag = magnesita

estructura laminada original y se muestra como aparentemente masivo. En algunas láminas delgadas, estos yesos incluyen pequeños cristales de celestina y relictos de anhidrita.

Los carbonatos del Muschelkalk son únicamente de composición calcítica. Para los carbonatos de las formaciones Canelles y Lécera la composición es dominantemente dolomítica en las brechas y carbonatos micríticos, y calcítica en los niveles oolíticos. La presencia relativamente abundante de calcita en algunas brechas puede interpretarse como el resultado de su parcial desdolomitización y/o la precipitación de cementos tardíos de este mineral en grietas y pequeñas cavidades. El cuarzo, frecuente en la mayoría de las muestras analizadas, podría ser de neoformación (silicificación de carbonatos). El yeso en los carbonatos está en forma de cemento rellenando pequeñas cavidades. La presencia de arcillas y otros minerales detríticos es prácticamente nula.

\section{Discusión}

Desde un punto de vista sedimentológico, los yesos y carbonatos de las formaciones Canelles y
Lécera se originaron en ambientes evaporíticos similares (Ortí et al., 2017). Ambos casos representan el desarrollo de lagoons sulfatados, muy estables, alimentados por aguas marinas, con sedimentación de yeso o carbonato, respectivamente, en estadios de relativa concentración o dilución de sus aguas. A diferencia de otros ambientes evaporíticos marinos, estos lagoons se caracterizan por: (1) una práctica ausencia de niveles detríticos finos (limos, arcillas); (2) la precipitación de yeso principalmente con litofacies laminada (sólo ocasionalmente facies nodulares); y (3) la ausencia de sales más solubles (halita). La ausencia de detríticos sería el resultado de su relativa lejanía respecto al área fuente. La uniformidad de litofacies laminadas representa el carácter estable de los lagoons, sin registro de estadios de desecación y sabkhatización. La ausencia de niveles de sal sería el resultado de la eliminación de las salmueras más concentradas hacia el mar, o bien su drenaje hacia zonas evaporíticas más internas.

A pesar de estas características sedimentológicas comunes, ambas formaciones muestran en Camarasa notables diferencias entre sí. Por un lado está el tipo de litofacies desarrollado. Así, no hay facies oolíticas 
de carbonato en los yesos jurásicos, ni yesos masivos blancos en el Keuper. Por otro, el tipo de ciclicidad desarrollado es distinto en cada caso.

La segunda diferencia es especialmente relevante. Para el caso de la Fm. Canelles, la ciclicidad está limitada a la unidad intermedia. Este aspecto es común a los otros cortes de esta formación estudiados en la Zona Surpirenaica (Salvany \& Bastida, 2004). Se trata de ciclos de somerización (shallowing upward) esencialmente carbonatados, que empiezan con facies margodolomíticas y culminan con facies oolíticas. Las unidades yesíferas inferior y superior no muestran carácter cíclico. Por el contrario, la Fm. Lécera constituye en su conjunto una continua sucesión de ciclos esencialmente yesíferos, donde el carbonato tiene siempre escaso desarrollo. Las características de estos ciclos siguen un mismo patrón, con un nivel basal carbonatado de tipo brecha dolomítica y/o dolomicrita y, por encima, un tramo superior yesífero más desarrollado. Los ciclos más completos de la unidad superior de la Fm. Lécera representarían una evolución de carácter somerizante con una etapa inicial carbonatada de lagoon más profundo, una etapa intermedia menos profunda con sedimentación de yeso laminado gris, y una etapa superior de lagoon gradualmente más somero con sedimentación de yeso laminado y masivo blanco. Las capas de yeso masivo blanco pueden representar niveles laminados precozmente anhidritizados en los que en mayor o menor grado la anhidritización ha difuminado la estructura laminada original. Los ciclos de la unidad inferior sólo muestran facies de yeso laminado gris, y representarían una situación de lagoon profundo más estable.

El lagoon sulfatado representado por la Fm. Canelles sólo se ha identificado en las Sierras Marginales (Zona Surpirenaica meridional), siendo el corte de Camarasa el que representa un mayor desarrollo de esta unidad. En el área de Les Nogueres (Zona Surpirenaica septentrional), el Keuper inferior está representado por la Fm. Adons, equivalente lateral de la Fm. Canelles (Salvany \& Bastida, 2004). Esta formación está principalmente compuesta por margas versicolores y dolomías que constituyen facies de plataforma carbonatada abiertas por el Norte hacia el océano. Por el Sur, en el subsuelo de la Cuenca del Ebro y en la Cordillera Costero Catalana, el Keuper inferior está representado, respectivamente, por las formaciones K-1 de Jurado (1990) y Miravet de Salvany \& Ortí (1987), también equivalentes laterales de la Fm. Canelles. Las formaciones K-1 y Miravet, representan ambientes evaporíticos de plataforma interna, en este caso con una notable influencia de aportes de sedimentos arcillosos de origen aluvial distal. La unidad K-1 constituye un importante depocentro salino (pond halítico) rodeado por facies de salina sulfatada, identificado por sondeos en el subsuelo del sector aragonés de la Cuenca del Ebro. La Fm. Miravet representa el desarrollo de una extensa salina sulfatada con alternancia de facies laminadas y nodulares de yeso, en este caso con escaso registro de sal (Ortí \& Bayó, 1977).

El lagoon sulfatado representado por la Fm. Lécera tuvo una mayor extensión paleogeográfica que el de la Fm. Canelles. Al Sur de Camarasa, sus depósitos yesíferos se extienden por el subsuelo de la cuenca del Ebro (Castillo, 1974; Gómez et al., 2007), y hasta la rama aragonesa de la Cordillera Ibérica (Gómez et al., 1998, Ortí \& Salvany, 2004). Los diferentes cortes estudiados, en sondeos y afloramientos, muestran siempre una monótona sucesión de yesos (o anhidrita en subsuelo) con capas subordinadas de carbonatos, y sin niveles de sal, formando ciclos de características parecidas a los observados en Camarasa. Los yesos son generalmente laminados o masivos, pero también se han identificado facies seleníticas y nodulares que representarían el margen Sur de este extenso lagoon del NE peninsular (Ortí \& Salvany, 2004). Hacia el Norte de Camarasa (zona surpirenaica del Montsec y cuenca de Graus-Tremp), las facies de lagoon sulfatado de la Fm. Lécera pasan lateralmente a depósitos carbonatados, en facies de brecha dolomítica (Delmás et al., 1971; Garrido \& Ríos, 1974). Un cambio lateral de facies parecido se da en la Cordillera Ibérica oriental (Gómez et al., 1998). En la Cordillera Costero Catalana las facies de lagoon sulfatado de la Fm. Lécera no están desarrolladas. En su lugar tenemos también una potente unidad de brechas carbonatadas sedimentarias, principalmente expuestas en la Mesa de Prades (Giner, 1978).

En el NE peninsular existen otras unidades evaporíticas triásicas con características de lagoon sulfatado similares a las representadas por las formaciones Canelles y Lécera. Estas unidades son: los Yesos de Paüls de la base del Muschelkalk medio de la Cordillera Costero Catalana (Ortí et al., en preparación), los Yesos de 
Senterada del Keuper superior de la Zona Surpirenaica septentrional (Salvany \& Bastida, 2004), los Yesos de Ayora (K5) del Keuper superior de la Cordillera Ibérica (Ortí, 1987), y probablemente también (no hay una descripción precisa de litofacies) la unidad anhidrítica superior (K-3) del Keuper del subsuelo de la Cuenca del Ebro (Jurado, 1990). En Ortí et al. (2017) se expone la relación estratigráfica, sedimentológica y paleogeográfica de todas ellas y sus unidades asociadas.

\section{Conclusiones}

Las formaciones yesíferas del Keuper inferior (Fm. Canelles) y Jurásico Inferior (Fm. Lécera) de Camarasa muestran aspectos litológicos y estratigráficos similares, pero también importantes diferencias entre sí.

Las similitudes entre ambas formaciones son las siguientes: (1) las dos están dominantemente formadas por capas de yesos laminados secundarios (alabastrinos), con niveles carbonatados subordinados; (2) no presentan prácticamente niveles de sedimentos detríticos finos; (3) muestran una total ausencia de facies nodulares de yeso.

Las diferencias entre ambas formaciones son las siguientes: (1) el tipo de carbonatos que presentan: principalmente brechas dolomíticas en la Fm. Lécera, y margodolomías, dolomicritas y calizas oolíticas en la Fm. Canelles; (2) el tipo de yesos: laminados grises o blancos y masivos blancos en la Fm. Lécera, y laminados blancos con tonos marrones en la Fm. Canelles. Además, al microscopio, los yesos de la Fm. Canelles muestran una textura pseudomórfica característica de cristales prismáticos de anhidrita (ahora como yeso secundario) mezclados con carbonato que no se reconoce en los yesos de la Fm. Lécera; (3) el tipo de ciclicidad: presente en toda la serie de la Fm. Lécera, con alternancia de capas de carbonato y yeso en ciclos de gran espesor (hasta $33 \mathrm{~m}$ ), y limitada sólo a la unidad intermedia de la Fm. Canelles, con un tipo de ciclos esencialmente carbonatado, que presentan un nivel margodolomítico basal, uno intermedio dolomicrítico con yeso, y uno superior oolítico.

Desde un punto de vista sedimentológico, ambas formaciones corresponden a ambientes evaporíticos similares. En ambos casos son sedimentos de yeso y carbonato depositados en lagoons sulfatados alimentados por aguas marinas, con prácticamente nula influencia de aportes detríticos continentales. En estos lagoons no es común el registro de sales solubles (halita) pues las salmueras más concentradas fueron eliminadas hacia el mar abierto o bien hacia zonas evaporíticas más internas. Ello sugiere, para estas formaciones (Fm. Lécera y Fm. Canelles), una probable ausencia de niveles de sal en subsuelo. Este no sería el caso de la Fm. Boix, aquí no estudiada, que representa un ambiente evaporítico bien diferente, que sí que dio lugar a importantes niveles de sal mezclados con anhidrita, preservados en el subsuelo de esta formación.

\section{AGRADECIMIENTOS}

El presente estudio ha sido en parte financiado por el proyecto CGL2016-79458-P (Ministerio de Economía, Industria y Competitividad), en el marco del grupo de Geologia Sedimentària de la UB. El autor agradece la revisión crítica del manuscrito por parte de Federico Ortí, de la Universidad de Barcelona, y de los dos revisores: Marcos Aurell, de la Universidad de Zaragoza, y Laura Rosell, de la Universidad de Barcelona, que ha permitido mejorar el contenido y redacción del mismo.

\section{Referencias}

Arnal, I.; Calvet, F.; Márquez, L.; Márquez-Aliaga, A. \& Solé De Porta, N. (2002). La plataforma carbonatada epeírica (formaciones Imón e Isábena) del Triásico superior del Noreste de la Península Ibérica. Acta Geológica Hispánica, 4: 299-328.

Cadillac, H.; Canerot, J. \& Fauré, Ph. (1981). Le Jurassique Inferieur aux confins des Iberides et des Catalanides (Espagne). Estudios Geológicos, 37: 187-198.

Calvet, F.; Márquez, L. \& Trifonova, E. (1994). Litoestratigrafía y bioestratigrafía (foraminíferos) de las facies Muschelkalk del Triásico Sudpirenaico y del Pirineo Vasco (España). Boletín de la Real Sociedad Española de Historia Natural (Sección Geología), 89(1-4): 167-188.

Castillo Herrador, F. (1974). Le Trias évaporitique des basins de la Vallée de l'Èbre et de Cuenca. Bulletin de la Société Géologique de France, 7(6): 666-676.

Delmás, M.; Garrido, A. \& Ríos, L.M. (1971). Contribución al estudio del Jurásico de la cuenca de GrausTremp (provincias de Huesca y Lérida). Cuadernos de Geología Ibérica, 2: 591-606.

Fauré, Ph. (1984). Le Lias de la partie centro-orientale des Pyrénées espagnoles (Provinces de Huesca, Lerida et Barcelona). Bulletin de la Société d'Histoire Naturelle de Toulouse, 121: 23-37. 
Garrido Megías, A. \& Ríos Aragüés, L.M. (1972). Síntesis geológica del Secundario y Terciario entre los ríos Cinca y Segre. Boletín Geológico y Minero, 83: $1-47$.

Giner, J. (1978). Origen y significado de las brechas del Lías de la Mesa de Prades (Tarragona). Estudios Geológicos, 34: 529-533.

Gómez, J.J. \& Goy, A. (1998). Las unidades litoestratigráficas del tránsito Triásico-Jurásico en la región de Lécera (Zaragoza). Geogaceta, 23: 63-66.

Gómez, J.J.; Goy, A. \& Barrón, E. (2007). Events around the Triassic-Jurassic boundary in northern and eastern Spain: A review. Palaeogeography, Palaeoclimatology, Palaeoecology, 244: 89-110. https://doi. org/10.1016/j.palaeo.2006.06.025

IGC (2006). Mapa Geològic Comarcal de Catalunya 1:50.000, $\mathrm{n}^{\mathrm{o}} 23$, Noguera. Generalitat de Catalunya.

IGC (2010). Atles Geològic de Catalunya. Generalitat de Catalunya, 463 pp.

Jurado, M.J. (1990). El Triásico y el Liásico basal evaporíticos del subsuelo de la cuenca del Ebro. In: Formaciones evaporíticas de la Cuenca del Ebro y cadenas periféricas, y de la zona de Levante (Ortí, F. \& Salvany, J.M., eds.). Universitat de Barcelona, 21-28.

Martínez Peña, M.B. \& Pocoví, A. (1988). El amortiguamiento frontal de la estructura de la cobertera surpirenaica y su relación con el anticlinal de Barbastro-Balaguer. Acta Geológica Hispánica, 23(2): 81-94.

Moragas, M.; Playà, E. \& Vergés, J. (2013). Overprinting of deformations in sedimentary facies in a Hettangian evaporite-carbonate sequence (Camarasa, South Pyrenees, Spain). Abstracts volume, 30th IAS Meeeting of Sedimentology, Manchester, UK.

Ortí, F. (1987). Aspectos sedimentológicos de las evaporitas del Triásico y del Liásico Inferior en el E de la Península Ibérica. Cuadernos de Geología Ibérica, 11: 837-858.

Ortí, F. \& Bayó, A. (1977). Características litoestratigráficas del Triásico Medio y Superior en el "Baix Ebre" (Tarragona-España). Cuadernos de Geología Ibérica, 4: 223-238.

Ortí, F. \& Salvany, J.M. (2004). Coastal salina evaporites of the Triassic-Liassic boundary in the Iberian Peninsula: the Alacón borehole. Geologica Acta, 2(4): 291-304.

Ortí, F.; Pérez-López, A. \& Salvany, J.M. (2017). Triassic evaporites of Iberia: sedimentological and palaeogeographical implications for the western Neotethys evolution during the Middle Triassic-earliest Jurassic. Palaeogeography, Palaeoclimatology, Palaeoecology, 471: 157-180. https://doi.org/10.1016/j. palaeo.2017.01.025

Pocoví, A. (1978a). Estudio geológico de las Sierras Marginales Catalanas (Prepirineo de Lérida). Tesis Doctoral, Universitat de Barcelona, 219 pp.

Pocoví, A. (1978b). Estudio geológico de las Sierras Marginales Catalanas (Prepirineo de Lérida). Acta Geológica Hispánica, 3: 73-79.

Salvany, J.M. \& Bastida, J. (2004). Análisis litoestratigráfico del Keuper surpirenaico central. Revista de la Sociedad Geológica de España, 17(1-2): 3-26.

Salvany, J.M. \& Ortí, F. (1987). El Keuper de los Catalánides. Cuadernos de Geología Ibérica, 11: 215-236.

Sáez, A. (1987). Estratigrafía y sedimentología de las formaciones lacustres del tránsito Eoceno-Oligoceno del NE de la cuenca del Ebro. Tesis Doctoral, Universitat de Barcelona, 352 pp.

Sáez, A.; Vergés, J.; Taberner, C.; Pueyo, J.J.; Muñoz, J.A. \& Busquets, P. (1991). Eventos evaporíticos paleógenos en la Cuenca Antepais Surpirenaica: ¿causas climáticas - causas tectónicas?. In: Libro-guía Excursión $n^{\circ} 5$ (Colombo, F., ed.), I Congreso del Grupo Español del Terciario, 85 pp.

Saula, E. \& Samsó, J.M. (1996). Estratigrafía y evolución tectónica de las láminas cabalgantes con sedimentos lutecienses en el manto de las Sierras Marginales (Unidad Surpirenaica Central). Geogaceta, 20(2): 458-461.

Serra, J.; Capdevila, J. \& Maestro, E. (1992). Descripción e interpretación de las litofacies evaporíticas de Artesa de Segre (Eoceno Superior del NE de la Cuenca del Ebro). Geogaceta, 11: 38-41.

Soto, R.; Pocoví, A. \& Santolaria, P. (2015). El sistema de pliegues y cabalgamientos oblicuos de St. Jordi-Sierra Boada (Sierras Marginales, Unidad Surpirenaica Central). Geogaceta, 58: 91-94.

Ullastre, J. \& Masriera, A. (1995). El Mesozoico de Artesa de Segre: precisiones estratigráficas y análisis tectónico-sedimentario del "frente" sudpirenaico entre Artesa y Camarasa (Pirineo catalán, España). Treba1ls del Museu de Geologia de Barcelona, 4: 181-209.

Ullastre, J. \& Masriera, A. (1996). Evolución tectónica de las unidades sudpirenaicas al W y al E de la línea de accidente del Segre (Pirineo catalán, España). Treballs del Museu de Geologia de Barcelona, 5: 213-253.

Vergés, J. (1993). Estudi geològic del vessant sud del Pirineu oriental i central. Evolució cinemática en 3D. Tesis Doctoral, Universitat de Barcelona: 203 pp. 